\title{
Female-biased dispersal and non-random gene flow of $M C 1 R$ variants do not result in a migration load in barn owls
}

\author{
Valérie Ducret $^{1} \cdot$ Michael Schaub $^{2} \cdot$ Jérôme Goudet ${ }^{1} \cdot$ Alexandre Roulin $^{1}$ \\ Received: 15 January 2018 / Revised: 18 June 2018 / Accepted: 19 June 2018 / Published online: 13 July 2018 \\ (c) The Genetics Society 2018
}

\begin{abstract}
Non-random gene flow is a widely neglected force in evolution and ecology. This genotype-dependent dispersal is difficult to assess, yet can impact the genetic variation of natural populations and their fitness. In this work, we demonstrate a high immigration rate of barn owls (Tyto alba) inside a Swiss population surveyed during 15 years. Using ten microsatellite loci as an indirect method to characterize dispersal, two-third of the genetic tests failed to detect a female-biased dispersal, and Monte Carlo simulations confirmed a low statistical power to detect sex-biased dispersal in case of high dispersal rate of both sexes. The capture-recapture data revealed a female-biased dispersal associated with an excess of heterozygote for the melanocortin-1 receptor gene $(M C 1 R)$, which is responsible for their ventral rufous coloration. Thus, female homozygotes for the $M C 1 R_{\text {WHITE }}$ allele might be negatively selected during dispersal. Despite the higher immigration of females that are heterozygote at $M C 1 R$, non-random gene flow should not lead to a migration load regarding this gene because we did not detect an effect of $M C 1 R$ on survival and reproductive success in our local population. The present study highlights the usefulness of using multiple methods to correctly decrypt dispersal and gene flow. Moreover, despite theoretical expectations, we show that non-random dispersal of particular genotypes does not necessarily lead to migration load in recipient populations.
\end{abstract}

\section{Introduction}

Unraveling the effect of natural selection and dispersal in shaping genetic and phenotypic variation is crucial to understand the impact of gene flow on local adaptation. Dispersal can counteract the effect of natural selection by introducing maladapted alleles into locally adapted populations (Slatkin 1987; $\mathrm{Hu}$ and $\mathrm{Li}$ 2003), an effect that depends on the strength of selection against immigrants and the alleles they carry (Lenormand 2002; Postma and van Noordwijk 2005). This is referred to as "migration load,"

These authors contributed equally: Alexandre Roulin, Jérôme Goudet.

Electronic supplementary material The online version of this article (https://doi.org/10.1038/s41437-018-0115-9) contains supplementary material, which is available to authorized users.

Valérie Ducret

valerie.ducret@gmail.com

1 Department of Ecology and Evolution, University of Lausanne, Biophore Building, CH-1015 Lausanne, Switzerland

2 Swiss Ornithological Institute, CH-6204 Sempach, Switzerland when the fitness of a population decreases as a result of the immigration of locally less fit alleles (Garcia-Ramos and Kirkpatrick 1997; Bolnick and Nosil 2007). However, the absence of dispersal, and consequently gene flow, can limit local adaptation due to decreased genetic variation on which natural selection can work (Bourne et al. 2014). Dispersal can indeed potentially facilitate the exchange of adaptive variation between populations (Bolnick and Otto 2013; PortnFulgioneoy et al. 2015; Fulgione et al. 2016) or even among closely related species that hybridize (Fraisse et al. 2014; Palmer and Kronforst 2015).

Gene flow plays a major role in evolutionary processes, but its effects are generally complex (Ciani and Capiluppi 2011; Edelaar and Bolnick 2012; Bolnick and Otto 2013). Dispersal is often not a set of random individuals moving between populations, but instead can be enriched for certain phenotypes and underlying genotypes, as shown in humans for the DRD4 gene, which is associated with novelty seeking and hyperactivity traits (Chen et al. 1999). Dispersal is also often sex biased in vertebrates [e.g., female biased in common frogs Rana temporaria (Palo et al. 2004) or in cougars Puma concolor (Biek et al. 2006); male biased in white-throated magpie-jays Calocitta formosa (Berg 
et al. 2009) or in tortoises Astrochelys radiate (Paquette et al. 2010)] meaning that dispersal and gene flow could differentially impact male and female fitness (Tarka et al. 2014; Camacho et al. 2013). Thus, describing gene flow based on particular genotypes or gender is important to understand how dispersal could favor or constrain the adaptive effects of natural selection within populations in a sex-specific manner (Edelaar and Bolnick 2012).

In natural populations, dispersal and gene flow can be estimated with direct methods that measure the movement of individuals through capture-recapture (Conrad et al. 1999; Baguette 2003; Schtickzelle et al. 2006) or GPS-tracking methods (Cooke et al. 2004; Ropert-Coudert and Wilson 2005). However, the direct assessment of dispersal can be difficult or inaccurate, such as in smaller-sized organisms, which preclude direct marking, or in large populations, where a relatively small proportion of animals can be marked, which impede detection of dispersers. Indirect methods based on genetic data offer an alternative approach to estimate dispersal and gene flow by comparing genotype frequencies between populations (Wright 1943; Wright 1951; Slatkin 1985) or between sexes (Goudet et al. 2002; Hansson et al. 2003). In many instances indirect methods are inaccurate in estimating gene flow or population divergence, for example, when individual movements are asymmetric between populations (Boileau et al. 1992; Knutsen et al. 2011). This is why the combination of direct and indirect approaches is useful to underline the importance of dispersal and gene flow in shaping neutral genetic variation (Slatkin 1985), as shown in damselfly Coenagrion mercuriale (Watts et al. 2007), Atlantic cod Gadus morhua (Knutsen et al. 2011), alpine salamander Salamandra atra (Helfer et al. 2012), and social weavers Philetairus socius (van Dijk et al. 2015), or in shaping phenotypic and neutral genetic variation in blue tits Cyanistes caeruleus (Garcia-Navas et al. 2014). However, further empirical studies that combine both methodologies to clarify the effect of dispersal and gene flow in shaping adaptive genetic variation are required because most studies performed so far considered only neutral genetic markers.

The European barn owl (Tyto alba) is an appropriate model system to study the effect of dispersal on neutral and adaptive genetic variation. The striking variation of its pheomelanin-based coloration is associated with a nonsynonymous mutation at the melanocortin-1 receptor gene $(M C 1 R)$ (San-Jose et al. 2015; Burri et al. 2016), a key element in the vertebrate melanin synthesis pathway (Bennett and Lamoreux 2003). The valine allele (hereafter referred to as $\mathrm{V}$, white, allele) is strongly related with a white ventral plumage coloration, whereas the isoleucine (hereafter referred to as I, rufous, allele) relates to a redder plumage coloration and seems always partially dominant over the white allele. The pheomelanin coloration and its underlying $M C 1 R$ alleles vary clinally in Europe, from high frequency of the $M C 1 R_{\text {WHITE }}$ allele in the Iberian Peninsula to a high frequency of the $M C 1 R_{\text {RUFOUS }}$ allele in northeast Europe, while both mutations occur at intermediate frequencies in Central Europe (Antoniazza et al. 2010; Burri et al. 2016). At neutral markers, a significant albeit weak differentiation between European populations $\left(F_{\mathrm{st}}=0.011\right.$; 99\% CI: 0.007-0.016, see Antoniazza et al. 2010) highlights high gene flow at the level of the continent. Therefore, the maintenance of both genetic and phenotypic clines, despite strong gene flow, supports the presence of local adaptation (Antoniazza et al. 2010), as demonstrated through ABC simulations (Antoniazza et al. 2014). On a smaller spatial scale, there is also evidence for local adaptation in Switzerland, where coloration of females matches specific habitat types (Dreiss et al. 2012) and coloration is related to different prey-predator strategies (Roulin 2004; Charter et al. 2012). Moreover, the MCIR $R_{\text {RUFOUS }}$ mutation seems to be recurrently counter-selected in males at the juvenile stage (Ducret et al. 2016).

Here, we explore the effect of dispersal on the frequency of $M C 1 R$ variants in breeding barn owls of a Swiss population. First, we investigated if $M C 1 R$ genotypes deviate from Hardy-Weinberg equilibrium and if the deviation is different in male and female breeders, which could be caused by the effect of sex-specific selection and/or sexbiased dispersal. To disentangle which of these two processes is the most likely cause of a deviation, we also analyzed Hardy-Weinberg at ten neutral genetic markers (microsatellite loci). Because the Swiss barn owl population is at an intermediate position along the European cline, we would expect gene flow to cause a deficit rather than excess of heterozygotes for both microsatellites and MC1R. This is due to the genetic admixture of differentiated populations (containing a high proportion of homozygous individuals) from each extremity of the cline, also known as the Wahlund effect (Wahlund 1928). We analyzed capture-recapture data and neutral genetic data, respectively, direct and indirect methods, to characterize and estimate immigration rate of the $M C 1 R$ genotypes and to test if dispersal is female biased, as generally found in birds (Trochet et al. 2016). Lastly, we tested for sex-specific selection on MCIR genotypes in adults by analyzing reproductive success and survival.

\section{Materials and methods}

\section{Data collection}

The study was performed from 1998 to 2016 in an area of $1070 \mathrm{~km}^{2}$ in western Switzerland, where wild breeding barn owls were captured in artificial nest boxes. During the study 
period, we captured between 22 and $125($ mean = 57) breeding pairs annually. Clutch size and number of fledglings (i.e., viable offspring up to the fledging stage) were recorded for each nest, and all nestlings and 90\% of breeding adults were captured and marked with aluminum rings since 1988. Ringing allowed us to differentiate adults born inside our study area (philopatric) from those born outside (immigrant). Immigrants were those ringed outside the area by amateur ornithologists or captured for the first time without a ring. Immigrants' age can be estimated based on the molting pattern of the primary wing feathers (Dreiss and Roulin 2010).

We collected and stored blood samples of all captured barn owls at $-80{ }^{\circ} \mathrm{C}$ until DNA extraction. DNA was extracted using the DNeasy Tissue and Blood kit or the Biosprint robot (Qiagen). We determined MC1R genotypes for all adults by allelic discrimination (see protocol in SanJose et al. 2015). The allelic discrimination (AD) assay is a methodology using fluorescent markers of mutant and wildtype probes that provides a rapid and sensitive method for detecting known polymorphisms. Each probe consists of an oligonucleotide with a $5^{\prime}$ reporter dye and a $3^{\prime}$ quencher dye. In our case, the fluorescent markers of mutant and wild-type probes are ATTO550 and FAM, respectively (Microsynth). Therefore, if at the end of the qPCR there is fluorescence from only the reporter (FAM) for the wild-type allele, the sample is typed as VV. Fluorescence from only the ATTO550 reporter represents homozygosity for the mutant allele and is genotyped as II. Intermediate fluorescence from both reporters represents heterozygotes (VI). In each assay, we ran positive controls for each genotype and each sample was run in duplicate with two different PCRs. Only adults from 1998 to $2012(N=755)$ were genotyped for ten polymorphic microsatellite loci in two sets of multiplex. Genotyping procedure and description of multiplex sets (named 3 and 4) are described by Burri et al. (2016). Thus, the genetic analyses were constrained to the period 1998-2012, comprising the samples of 316 males and 439 females. They were used to estimate sex-biased dispersal and Hardy-Weinberg proportions at both $M C 1 R$ and microsatellites and for assignment tests.

\section{Genetic analyses}

\section{MC1R proportions}

Deviation from Hardy-Weinberg equilibrium $\left(F_{\mathrm{IS}}\right)$ at $M C 1 R$ was computed for each year using FSTAT v2.9.3 (Goudet 1995) and the difference between males and females on the range of $F_{\text {IS }}$ values was tested using Wilcoxon signed-rank test. We tested for differences in the proportion of MC1R genotypes between immigrant and philopatric males and females using a Fisher's exact test and computed the $F_{\text {IS }}$ values per sex and dispersal status (i.e., resident vs. immigrant) with FSTAT.

\section{Sex-biased dispersal}

The difference in the proportion of immigrants between the two sexes was assessed by means of a $\chi^{2}$-test using capture-recapture data. In addition, we used microsatellite data to detect female-biased dispersal by quantifying the mean assignment index $\left(\mathrm{mAI}_{\mathrm{c}}\right)$ and variance of the assignment index $\left(\mathrm{vAI}_{\mathrm{c}}\right)$ separately for both sexes using the $\mathrm{R}$ package HIERFSTAT (Goudet 2005; R Core Team 2013) and significant differences were determined using a onetailed permutation test $(N=1000)$. Deviations from Hardy-Weinberg equilibrium $\left(F_{\text {IS }}\right)$ per year of sampling were also computed using FSTAT and differences between males and females on the range of $F_{\mathrm{IS}}$ values were tested using the Wilcoxon signed-rank test. Sex-biased dispersal is expected to result in a lower $\mathrm{mAI}_{\mathrm{c}}$ and larger $\mathrm{vAI}_{\mathrm{c}}$ in the dispersing sex as well as positive $F_{\text {IS }}$ values due to a stronger Wahlund effect among adults of the dispersing sex (see Goudet et al. 2002).

\section{Individual-based Monte Carlo simulations}

The large percentage of immigrants (71\%), calculated from the capture-recapture data of adults, compared to residents in our study area and the fact that the tests were performed on a single population may decrease the sensibility of the $\mathrm{mAI}_{\mathrm{c}}$ and $\mathrm{vAI}_{\mathrm{c}}$ tests in detecting sex-biased dispersal. Therefore, we estimated the statistical power of $\mathrm{mAI}_{c}$ and $\mathrm{vAI}_{\mathrm{c}}$ using individual-based Monte Carlo simulation from EASYPOP (Balloux 2001), with the dispersal rate of males and females estimated by capture-recapture (respectively, $d_{\mathrm{m}}=0.62$ and $d_{\mathrm{f}}=0.78$ ) and with ten simulated loci. Dispersal followed an island model, the chosen mutation rate was 0.001 with 25 allelic states and the KAM mutation model (see detailed description of the parameters by Goudet et al. 2002). The simulation ran with ten populations containing each 50 males and 50 females, which represent the average annual number of breeding males and females in our study area. To achieve mutation-migrationdrift equilibrium, each of 99 replicates was run for 1000 generations. We also simulated a higher sex-biased dispersal, once with a total dispersal rate similar to the previous simulation $\left(d_{\mathrm{m}}=0.5\right.$ and $\left.d_{\mathrm{f}}=1.0, d_{\mathrm{t}}=0.75\right)$, and then with a lower total dispersal rate $\left(d_{\mathrm{m}}=0\right.$ and $d_{\mathrm{f}}=0.5$, $d_{\mathrm{t}}=0.25$ ). Finally, we applied the $\mathrm{mAI}_{\mathrm{c}}$ and $\mathrm{vAI}_{\mathrm{c}}$ tests using HIERFSTAT to a single or all-simulated populations and for each replicate. Thus, we defined the statistical power of the two tests in detecting female-biased dispersal as the number of times the tests were significant $(P \leq 0.05)$ over the 99 replicates. 


\section{Fitness components}

To estimate fitness, we measured survival and reproductive success of the $M C 1 R$ genotypes. Because homozygotes for the $M C 1 R_{\text {RUFOUS }}$ were rare $(\sim 3 \%)$, we distinguished genotypes as carrying at least one vs. no copy of the $M C 1 R_{R U}$ Fous allele (i.e., II/VI vs. VV).

\section{Survival probability}

Annual capture-recapture data of adult barn owls that have been collected in our study area from 1998 to 2016 were analyzed with Cormack-Jolly-Seber (CJS) models (Lebreton et al. 1992) using the program MARK (White and Burnham 1999). Nine hundred ninety-six captured adults were sexed, genotyped at $M C 1 R$ (II/VI vs. VV), with known dispersal status (either locally born or immigrant) and thus constituted eight groups of individuals. We estimated apparent survival $(\varphi)$, which is the probability to survive and to remain in the study area. Although we cannot distinguish between mortality and emigration, both processes lead to similar effects on the fitness of individuals at the local population level. We estimated the recapture probabilities $(\rho)$, which is the probability to recapture a marked individual present in the study area. We started with a general model that assumed survival to vary over time in each of the eight groups independently from each other and for which the recapture probability varied over time in males and females independently from each other. In the first modeling step, we verified whether survival and recapture probabilities varied over time and whether temporal variation was additive to the group effects. In the second modeling step, we kept the recapture model at the most parsimonious structure and modeled the effects of the eight groups on survival. Specifically, we fitted all possible models including single effects of sex, dispersal status, $M C 1 R$ genotype, and their two-way and three-way interactions. At each step, we fitted several candidate models that were ranked based on Akaike Information Criterion corrected for small sample sizes $\left(\mathrm{AIC}_{\mathrm{c}}\right.$ : Burnham et al. 2011). We verified the goodness-of-fit of the most complex model with the program U-CARE (Choquet et al. 2009). This test showed a good fit $\left(\chi^{2}=102.08, \mathrm{df}=159, P=\right.$ 0.99).

\section{Reproductive success}

We analyzed components of reproductive success in each nest from 1998 to 2016 with respect to sex, dispersal status (immigrant vs. resident), and $M C 1 R$ genotypes (II/VI vs. $\mathrm{VV}$ ) using generalized linear mixed models (GLMMs with single effects and their two-way and three-way interactions). Clutch size and the number of fledglings produced were analyzed using Poisson errors, whereas fledging success (probability that an egg become a fledgling) was analyzed using binomial errors. In all models, the laying date was incorporated as covariate and standardized (scaled and centered) to ease model convergence. Adults' and sites' identities and year were incorporated as random factors to account for spatial and temporal pseudo-replication. Competing models were ranked based on the $\mathrm{AIC}_{\mathrm{c}}$ using the function "dredge" of package MuMIn (Barton 2016) and the model with the lowest $\mathrm{AIC}_{\mathrm{c}}$ score was selected as the best-fitting model. Overdispersion was checked for all models using the function "overdisp.glmer" of the package RVAideMemoire (Hervé 2016). The statistical analyses were conducted with the R software v3.2.4 (R Core Team 2013).

\section{Results}

\section{Hardy-Weinberg proportion at microsatellites and MC1R}

A total of 105 alleles were found across the ten microsatellite loci. The number of alleles per locus ranged from 4 (locus Ta202) to 25 (locus Ta402). Randomization of alleles within sampling years indicated that in males one marker presented significant positive $F_{\text {IS }}(0.154)$ and two markers significant negative $F_{\mathrm{IS}}(-0.061$ and -0.1$)$ after Bonferroni correction $(P<0.001$; Table 1$)$. In females, one marker (Ta212) presented significant positive $F_{\mathrm{IS}}(0.062)$ after Bonferroni correction $(P<0.001$; Table 1). We discovered

Table $1 F_{\text {IS }}$ values in adult male and female barn owls for ten microsatellite loci averaged over 1998-2012

\begin{tabular}{llllll}
\hline & \multicolumn{2}{l}{ Males } & & \multicolumn{2}{l}{ Females } \\
\cline { 2 - 3 } \cline { 5 - 6 } & $F_{\text {IS }}$ & $P$ values & & $F_{\text {IS }}$ & $P$ values \\
\hline Ta202 & 0.154 & $<\mathbf{0 . 0 0 1}$ & & 0.037 & 0.108 \\
Ta204 & 0.010 & 0.340 & & 0.008 & 0.362 \\
Ta212 & -0.030 & 0.058 & & 0.062 & $<\mathbf{0 . 0 0 1}$ \\
Ta214 & 0.016 & 0.253 & & 0.029 & 0.087 \\
Ta215 & -0.025 & 0.181 & & 0.046 & 0.049 \\
Ta305 & -0.023 & 0.169 & & 0.047 & 0.033 \\
Ta310 & -0.100 & $<\mathbf{0 . 0 0 1}$ & 0.036 & 0.068 \\
Ta402 & -0.012 & 0.153 & & -0.028 & 0.009 \\
Ta408 & 0.009 & 0.338 & & -0.051 & 0.003 \\
Ta413 & -0.061 & $<\mathbf{0 . 0 0 1}$ & -0.003 & 0.392 \\
\hline$P$
\end{tabular}

$P$ values correspond to the proportion of randomizations that gave a larger or a smaller $F_{\text {IS }}$ than the observed value (respectively, when $F_{\text {IS }}$ is positive or negative). Bold $P$ values indicate significant deviation from HW proportion under a risk $\alpha=0.05$ and after Bonferroni correction ( $P$ value is divided by 10 (number of loci tested) and by 2 (number of sex tested, i.e., $P<0.0025)$ ) 

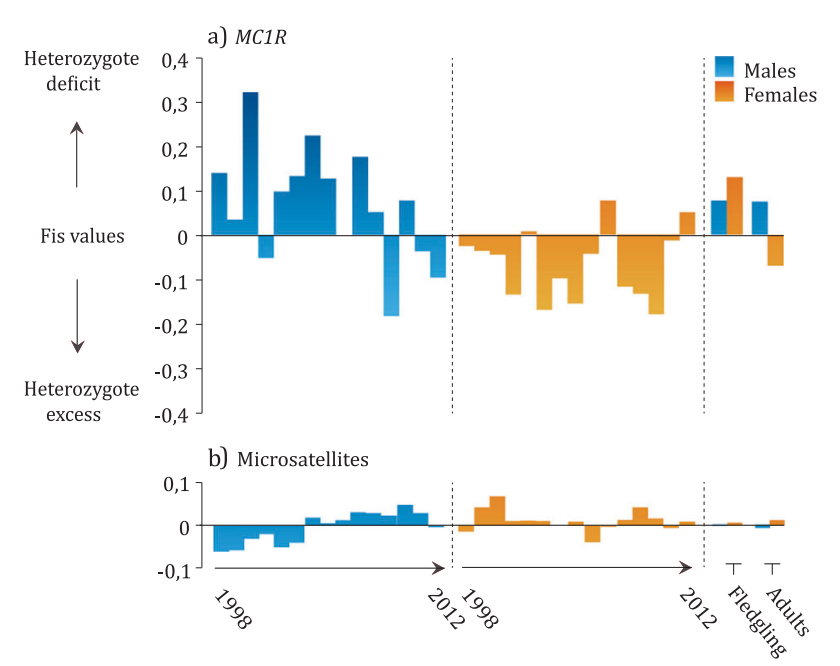

Fig. $1 F_{\text {IS }}$ values computed for $M C 1 R$ and microsatellites and averaged over loci per year of sampling and sex in breeding barn owls. Positive and negative values represent, respectively, deficit and excess of heterozygote at $M C 1 \mathrm{R}$ or microsatellites

the presence of null alleles for this marker and we removed it for all adults in the subsequent analyses. Also, females did not show significantly higher annual $F_{\text {IS }}$ values (average $F_{\text {IS }}=0.011, F_{\text {IS }}$ year-range $=-0.039$ to 0.067$)$ than males (average $F_{\text {IS }}=-0.005, F_{\text {IS }}$ year-range $=-0.061$ to 0.047 ) (Wilcoxon sum rank test, $W=131, P=0.23$ ).

The pattern at $M C 1 R$ was different compared to neutral markers. Adult females showed a significantly higher excess of heterozygotes (average $F_{\text {IS }}=-0.069, F_{\text {IS }}$ yearrange $=-0.18$ to 0.076 ) than males (average $F_{\mathrm{IS}}=0.077$, $F_{\text {IS }}$ year-range $=-0.182$ to 0.319 ) (Wilcoxon rank sum test, $W=42.5, P=0.004$; Fig. 1).

\section{Dispersal and gene flow}

Our capture-recapture data indicated that only $29 \%$ of the adults breeding in our study area were born inside the study area. The proportion of locally born breeders was higher in males compared to females (38\% vs. $22 \%$; Chi-square test, $\chi^{2}=24.26, P<0.001$; Table 2). Using microsatellite data, we observed a weak but significantly higher variance assignment index for females than for males (respectively $\mathrm{vAI}_{\mathrm{cf}}=11.03, \mathrm{vAI}_{\mathrm{cm}}=9$; permutation test, $P=0.021$ ), but the mean assignment index $\left(\mathrm{mAI}_{\mathrm{c}}\right)$ was close to 0 in both sexes $(P=0.48)$.

In females, immigrants were more often heterozygous for the MCIR gene than residents (Fisher's exact test, $P=$ 0.042 ), while in males we did not find such a difference $(P=0.93$; Table 2$)$. Those differences in the level of heterozygosity between immigrants and residents within each sex were reflected in the $F_{\text {IS }}$ values, although the deviations were not significant. Philopatric females showed an excess of homozygotes $\left(F_{\mathrm{IS}}=0.197, P=0.05\right)$ and immigrant
Table 2 Numbers and percentages of $M C 1 R$ genotypes in philopatric and immigrant male and female barn owls breeding in western Switzerland between 1998 and 2012

\begin{tabular}{llrrr}
\hline & II & \multicolumn{1}{l}{ VI } & \multicolumn{1}{l}{ VV } & Total \\
\hline Males & & & & \\
Philopatric & $4(3.3 \%)$ & $31(25.4 \%)$ & $87(71.3 \%)$ & 122 \\
Immigrant & $7(3.6 \%)$ & $54(27.8 \%)$ & $133(68.6 \%)$ & 194 \\
Females & & & & \\
Philopatric & $5(5.2 \%)$ & $21(21.9 \%)$ & $70(72.9 \%)$ & 96 \\
Immigrant & $5(1.5 \%)$ & $101(29.4 \%)$ & $237(69.1 \%)$ & 343 \\
\hline
\end{tabular}

II: homozygotes for the rufous allele, VI: heterozygotes, VV: homozygotes for the white allele

females a slight excess of heterozygotes $\left(F_{\text {IS }}=-0.084\right.$, $P=0.1$, whereas we observed a slight excess, albeit nonsignificant, of homozygotes in both philopatric $\left(F_{\mathrm{IS}}=\right.$ $0.058, P=0.33)$ and immigrant males $\left(F_{\mathrm{IS}}=0.040, P=\right.$ $0.35)$.

\section{Statistical power of $\mathrm{vAl}_{\mathrm{c}}$ and $\mathrm{mAl}_{\mathrm{c}}$ tests}

The $\mathrm{mAI}_{\mathrm{c}}$ and $\mathrm{vAI}_{\mathrm{c}}$ tests have a very low power to detect female-biased dispersal when the dispersal rate is as high as observed in our study population $\left(d_{\mathrm{m}}=0.62\right.$ and $\left.d_{\mathrm{f}}=0.78\right)$. Only $2 \%$ and $6 \%$ of the replicates had a significant $\mathrm{vAI}_{\mathrm{c}}$ and $\mathrm{mAI}_{\mathrm{c}}$ test, respectively. The statistical power did not increase when, for a similar mean dispersal rate, the sexbiased dispersal increased $\left(d_{\mathrm{m}}=0.5\right.$ and $\left.d_{\mathrm{f}}=1.0\right)$ with $6 \%$ and $7 \%$ of the replicates having significant $\mathrm{vAI}_{\mathrm{c}}$ and $\mathrm{mAI}_{\mathrm{c}}$ tests, respectively. The power of the $\mathrm{mAI}_{\mathrm{c}}$ and $\mathrm{vAI}_{\mathrm{c}}$ tests did not differ and was always very low when the tests were performed on a single or on all-simulated populations.

With a reduced average dispersal rate $(0.25)$ but with the same strong sex-biased dispersal as previously $\left(d_{\mathrm{m}}=0.0\right.$ and $d_{\mathrm{f}}=0.5$ ), the power of the two tests increased drastically with $50 \%$ and $92 \%$ of the replicates having significant $\mathrm{vAI}_{\mathrm{c}}$ and $\mathrm{mAI}_{\mathrm{c}}$ tests, respectively, and when the tests were performed on the data containing the ten populations. If the tests were performed on a single population, the $\mathrm{vAI}_{\mathrm{c}}$ test became significant in only $9 \%$ of the cases, whereas the $\mathrm{mAI}_{\mathrm{c}}$ test was significant in $30 \%$ of the cases. The lower statistical power of the $\mathrm{vAI}_{\mathrm{c}}$ compared to the $\mathrm{mAI}_{\mathrm{c}}$, when the dispersal rate is low, was expected based on previous simulations (Goudet et al. 2002).

\section{Apparent survival in relation to $M C 1 R$}

The model with time-specific recapture probabilities and time-dependent survival probabilities with an additive group effect was by far the most parsimonious model (Table S1). Although the model with an additive sex effect on recapture probability was close to the best 
Table 3 Model selection results of apparent survival $(\varphi)$ of adult barn owls breeding in western Switzerland in function of time $(t:$ year), sex, dispersal status (status: immigrant vs. resident) and $M C 1 R$ genotypes $(M C 1 R$ : II/VI vs. VV)

\begin{tabular}{|c|c|c|c|c|c|}
\hline Model & $\mathrm{AIC}_{\mathrm{c}}^{\mathrm{a}}$ & $\Delta \mathrm{AIC}_{\mathrm{c}}^{\mathrm{b}}$ & $w^{\mathrm{c}}$ & K & Deviance \\
\hline$\varphi(\operatorname{Sex}+$ status $+t)$ & 2191.23 & 0.00 & 0.34 & 37 & 785.17 \\
\hline$\varphi(\operatorname{Sex}+$ status $+M C 1 R+t)$ & 2192.63 & 1.40 & 0.17 & 38 & 784.46 \\
\hline$\varphi(\operatorname{Sex}+$ status $+\operatorname{sex} *$ status $+t)$ & 2193.34 & 2.11 & 0.12 & 38 & 785.17 \\
\hline$\varphi(\operatorname{Sex}+$ status $+M C 1 R+\operatorname{sex} * M C 1 R+t)$ & 2193.80 & 2.57 & 0.09 & 39 & 783.51 \\
\hline$\varphi(\mathrm{Sex}+$ status $+M C 1 R+M C 1 R *$ status $+t)$ & 2194.27 & 3.04 & 0.07 & 39 & 783.98 \\
\hline$\varphi(\mathrm{Sex}+$ status $+M C 1 R+\operatorname{sex} *$ status $+t)$ & 2194.74 & 3.51 & 0.06 & 39 & 784.46 \\
\hline$\varphi(\operatorname{Sex}+$ status $+M C 1 R+\operatorname{sex} * M C 1 R+M C 1 R *$ status $+t)$ & 2195.14 & 3.91 & 0.05 & 40 & 782.73 \\
\hline$\varphi(\mathrm{Sex}+$ status $+M C 1 R+M C 1 R *$ status $+\operatorname{sex} *$ status $+t)$ & 2195.14 & 3.91 & 0.05 & 40 & 782.73 \\
\hline$\varphi(\operatorname{Sex}+$ status $+M C 1 R+\operatorname{sex} * M C 1 R+\operatorname{sex} *$ status $+t)$ & 2195.92 & 4.69 & 0.03 & 40 & 783.51 \\
\hline $\begin{array}{l}\varphi(\operatorname{Sex}+\operatorname{status}+M C 1 R+\operatorname{sex} * M C 1 R+\operatorname{sex} * \text { status }+ \text { status } * \\
M C 1 R+\operatorname{sex} * \text { status } * M C 1 R+t)\end{array}$ & 2199.05 & 7.83 & 0.01 & 42 & 782.41 \\
\hline$\varphi(\operatorname{Sex}+t)$ & 2199.40 & 8.17 & 0.01 & 36 & 795.45 \\
\hline$\varphi(\mathrm{Sex}+M C 1 R+t)$ & 2200.56 & 9.33 & 0.00 & 37 & 794.50 \\
\hline$\varphi(\operatorname{Sex}+M C 1 R+\operatorname{sex} * M C 1 R+t)$ & 2201.60 & 10.37 & 0.00 & 38 & 793.43 \\
\hline$\varphi($ Status $+t)$ & 2205.87 & 14.64 & 0.00 & 36 & 801.91 \\
\hline$\varphi(M C 1 R+$ status $+t)$ & 2207.69 & 16.46 & 0.00 & 37 & 801.62 \\
\hline$\varphi(M C 1 R+$ status $+M C 1 R *$ status $+t)$ & 2209.22 & 17.99 & 0.00 & 38 & 801.05 \\
\hline$\varphi(M C 1 R+t)$ & 2225.46 & 34.23 & 0.00 & 36 & 821.51 \\
\hline
\end{tabular}

Note that the model for recapture probability $(\rho)$ was always time dependent $(t)$ and is not included in the model notation. The most complex model for survival (i.e. (sex + status $+M C 1 R+\operatorname{sex} * M C 1 R+\operatorname{sex} *$ status + status $* M C 1 R+\operatorname{sex} *$ status $* M C 1 R+\mathrm{t}))$ corresponds exactly to model $(g+t)$ from the first modeling step (see Table S1)

$\mathrm{K}$ : Number of parameter estimated

Deviance: model deviance

${ }^{a} \mathrm{AIC}$ value corrected for small sample sizes

bDifference in a model's $\mathrm{AIC}_{\mathrm{c}}$ to the best-ranked model's $\mathrm{AIC}_{\mathrm{c}}$

${ }^{\mathrm{c}}$ Model weight: probability of the model given the data model, it did not improve the prediction of survival regarding sex, dispersal status, or $M C 1 R$ (Table S2). The best model with time-dependent recapture and apparent survival probabilities included an additive effect of sex and dispersal status on apparent survival (Table 3). Females had lower apparent survival than males $(\beta=$ $-0.526,95 \% \mathrm{CI}=-0.763$ to -0.288 ) and immigrants had lower apparent survival than locally born individuals $(\beta=-0.404,95 \% \mathrm{CI}=-0.652$ to -0.156$)$. An additive effect of $M C 1 R$ was observed in the second-best model $\left(\Delta \mathrm{AIC}_{\mathrm{c}}=1.40\right)$, where individuals with at least one copy of the rufous allele tended to have lower survival than homozygotes for the white allele $(\beta=-0.110,95 \% \mathrm{CI}=$ $-0.367-0.146)$.

\section{Reproductive success in relation to $M C 1 R$}

We did not find evidence that different $M C 1 R$ genotypes produced different clutch sizes, number of fledglings, and clutch success (Table 4). Only in the third best model, we detected a tendency for an interaction between sex and
$M C 1 R$ on the number of fledglings produced (GLMM Poisson, $\left.\chi^{2}=4.65, P=0.098\right)$, while the single effect of $M C 1 R$ was not significant $\left(\chi^{2}=0.77, P=0.38\right)$.

\section{Discussion}

Disentangling the effect of selection and dispersal in natural populations is often challenging because both processes interplay in shaping genetic and phenotypic variation. Particularly, we barely understand the consequences of dispersal in shaping adaptive variation as most studies use neutral genetic variation to disentangle the effect of dispersal and selection (Mullen and Hoekstra 2008; Antoniazza et al. 2010). Here, in a barn owl population breeding in Switzerland, we explored the effect of dispersal on the local frequency of $M C 1 R$ variants, a key two-alleles gene involved in vertebrate melanin synthesis pathway (Bennett and Lamoreux 2003) and suspected to be under local adaptation in Europe (Antoniazza et al. 2010, 2014). 
Table 4 Effects of $M C 1 R$ genotypes (MC1R: II/VI vs. VV), sex, dispersal status (status: immigrant vs. resident) and laying date (LD) on components of reproductive parameters of adult barn owls

\begin{tabular}{lrllll}
\hline Predictors & $\mathrm{AIC}_{\mathrm{c}}{ }^{\mathrm{a}}$ & $\Delta \mathrm{AIC}_{\mathrm{c}}{ }^{\mathrm{b}}$ & $w^{\mathrm{c}}$ & $\mathrm{K}$ & Deviance \\
\hline Clutch size & & & & & \\
$\mathrm{LD}$ & 8074.2 & 0.00 & 0.45 & 5 & 8064.1 \\
$\mathrm{LD}+$ status & 8074.9 & 0.74 & 0.31 & 6 & 8062.9 \\
$\mathrm{LD}+$ MC1R & 8075.4 & 1.27 & 0.24 & 6 & 8063.4 \\
Number of fledglings produced & & & & & \\
$\mathrm{LD}$ & 8830.0 & 0.00 & 0.31 & 5 & 8820.0 \\
$\mathrm{LD}+$ status + sex $*$ status & 8830.8 & 0.75 & 0.22 & 8 & 8814.7 \\
$\mathrm{LD}+$ MC1R + sex $*$ MC1R & 8830.8 & 0.77 & 0.21 & 8 & 8814.7 \\
$\mathrm{LD}+$ MC1R & 8831.6 & 1.60 & 0.14 & 6 & 8819.6 \\
$\mathrm{LD}+$ status & 8831.9 & 1.92 & 0.1 & 6 & 8819.9 \\
Clutch success & & & & & \\
LD & 7926.1 & 0.00 & 0.35 & 5 & 7916.1 \\
$\mathrm{LD}+$ status & 7926.5 & 0.41 & 0.29 & 6 & 7914.5 \\
$\mathrm{LD}+$ MC1R & 7927.2 & 1.10 & 0.20 & 6 & 7915.2 \\
$\mathrm{LD}+$ status + MC1R & 7927.7 & 1.61 & 0.16 & 7 & 7913.6 \\
\hline
\end{tabular}

Shown are the best models based on $\mathrm{AIC}_{\mathrm{c}}\left(\Delta \mathrm{AIC}_{\mathrm{c}} \leq 2\right)$

K: Number of parameter estimated

Deviance: model deviance

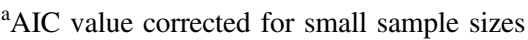

${ }^{b}$ Difference in a model's $\mathrm{AIC}_{\mathrm{c}}$ to the best-ranked model's $\mathrm{AIC}_{\mathrm{c}}$

${ }^{\mathrm{c}}$ Model weight: probability of the model given the data

\section{Comparison between direct and indirect estimates of sex-biased dispersal}

Direct and indirect methods to estimate sex-biased dispersal have different strengths and weaknesses, and hence are complementary. Direct methods are often difficult to apply in natural populations but indirect methods based on neutral markers are sometimes not powerful enough to detect effects. Our results from capture-recapture analyses based on long-term monitoring of a Swiss barn owl population highlighted an overall high dispersal rate (71\% of immigrants among breeding adults), which is in line with the low genetic differentiation at the scale of continental Europe due to intense gene flow (Antoniazza et al. 2010) and which seems to be common in other bird species as well (Schaub et al. 2013; Altwegg et al. 2014; Schaub et al. 2015). We also revealed that dispersal is female biased in barn owls, with $78 \%$ of females and $62 \%$ of males being immigrants.

The rate of immigration is so high in both sexes that the genetic (indirect) methods mostly failed to detect sex-biased dispersal with only the $\mathrm{vAI}_{c}$ tests being significant. Accordingly, using simulations, we find an extremely low power of the $\mathrm{mAI}_{\mathrm{c}}$ and $\mathrm{vAI}_{\mathrm{c}}$ tests to detect the observed female-biased dispersal, which is due to the very high dispersal rate in the Swiss population and the consideration of a single population (statistical power of the tests is higher if we compare dispersal between multiple populations). Because the assignment index tests are commonly performed on a single population or on small spatial scales (Chambers and Garant 2010; Liebgold et al. 2013; Harrison et al. 2014), we advise researchers to use several methods to estimate sex-biased dispersal in order to decrease the risk of type I and II errors. If dispersal rates are very large, indirect methods based on genetic markers will fail, because these methods assume the genotypes to represent a (imperfect) tag of the population where the individuals originated. In this situation, direct methods will probably generally be more powerful.

\section{Evolution of male-biased philopatry}

The most acknowledged hypothesis to explain the evolution of sex-biased dispersal is in Greenwood's seminal paper Greenwood (1980), which linked the directionality of sex-biased dispersal to mating systems in birds and mammals. Using a database of 257 species and phylogenetic approaches, a recent review by Trochet et al. (2016) proposed that the evolution of sex-biased dispersal was linked to parental care and sexual dimorphism rather than to mating system per se, a pattern congruent to other findings in birds (Mabry et al. 2013). Among raptors and owls, sex roles in reproduction are well defined with females incubating, brooding, and distributing the food among the progeny and males hunting most of the prey items (Sonerud et al. 2014). Thus, the survival of the brood relies strongly on the hunting efficiency of males. Familiarity with the environment to acquire resources and potentially to attract females should therefore restrict male's dispersal and favor their philopatry (Ortego et al. 2008; Pakanen et al. 2016).

Concordant with this hypothesis, our results show that locally born individuals had higher apparent survival than immigrants, particularly in males. Locally born individuals also tended to produce slightly more fledglings than immigrants. Although our survival analyses could not distinguish between mortality and permanent emigration, it conclusively indicates that locally born males have a higher probability to reproduce inside our study area compared to females and immigrants. Importantly, a previous study on the population dynamics of this barn owl population showed that emigration from our study area is almost inexistent in adults (emigration rate: 0.010, $\mathrm{SE}=0.014$; Altwegg et al. 2003) because emigration in Swiss barn owls occurs mainly in yearlings (van den Brink et al. 2012), suggesting that our estimate of apparent survival in adults is close to true survival and hardly affected by emigration. 


\section{Non-random dispersal}

Dispersal is often related to morphological, behavioral, and ecological traits, also known as dispersal syndromes (Cote et al. 2010; Ronce and Clobert 2012; Chakarov et al. 2013). When dispersal is biased toward one sex, the dispersal traits may be differentially expressed between sexes. This covariation between sexual dimorphism and sex-biased dispersal arises from phenotype-related costs and benefits associated to dispersal (Tarka et al. 2014; Pakanen et al. 2016), as suggested for example with the evolutionary loss of female coloration with migration among wood-warblers (Simpson et al. 2015). In barn owls, previous studies found evidence that females move farther than males during natal and breeding dispersal, although individuals' pheomelanic coloration better explained variation in natal dispersal than sex (van den Brink et al. 2012; Roulin 2013). The relationship between dispersal and color could be easily explained by either a greater net costs of being visible while dispersing (i.e., being dark rufous is expected to be a cryptic coloration than a white phenotype), owing to risks of being detected by visual predators (Simpson et al. 2015) or to the fact that the melanocortin system is implicated in the expression of many phenotypic traits such as melanism, physiology, and behavior (Ducrest et al. 2008; Roulin and Ducrest 2011; Reissmann and Ludwig 2013).

Our results highlight that females-the dispersing sexare more heterozygous than expected at $M C 1 R$, a gene with a valine-to-isoleucine substitution explaining $\sim 30 \%$ of variation in the pheomelanic coloration in this population (SanJose et al. 2015). Because homozygotes for the $M C 1 R_{R U}$ FOUS allele are rare in the Swiss population and in nearby populations (Burri et al. 2016), the high frequency of heterozygotes results mostly from a deficit of homozygotes for the $M C 1 R_{\text {WHITE }}$ allele in immigrant females. However, based on our data set, we cannot test if this deficit is due to a cost for females to display a white phenotype or an advantage of being heterozygous at $M C 1 R$ during dispersal. Future studies should compare individual's dispersal distance in populations where individuals are mainly white or dark rufous to further examine the effect of pheomelaninbased coloration on dispersal.

\section{Effect of sex-biased dispersal and non-random gene flow on fitness}

Dispersal is often sex biased in vertebrates (Palo et al. 2004; Biek et al. 2006; Berg et al. 2009; Paquette et al. 2010; Trochet et al. 2016). As a matter of fact, theoretical and empirical studies have demonstrated that immigration of maladapted alleles results in a reduction of mean fitness of the recipient populations, also known as "migration load" (Garcia-Ramos and Kirkpatrick 1997; Bolnick and Nosil
2007). Moreover, if one sex has evolved to remain in their native site (philopatry), migration load will impact specifically this sex resulting in fitness differences between the philopatric and the dispersing sex (Tarka et al. 2014; Camacho et al. 2013). Thus, describing gene flow based on particular genotypes or gender is important to understand how dispersal favors or constrains the adaptive effects of natural selection within populations in a sex-specific manner (Edelaar and Bolnick 2012). Our analysis of apparent survival showed that immigrants have a lower survival than locally born individuals. Thus, while immigration may decrease the mean fitness of the population by introducing maladapted alleles, this effect should be reduced by the lower survival, and consequently reproduction, of immigrants compared to locally born individuals. In addition, we found in the second-best model of apparent survival that the $M C 1 R_{R U F O U S}$ allele had only a weak and non-significant effect of decreasing apparent survival. Also, individuals carrying at least one copy of the $M C 1 R_{R U F O U S}$ allele did not produce significantly fewer eggs or fledglings. Both results suggest that, despite the higher immigration of females that are heterozygote at $M C 1 R$, non-random gene flow should not lead to a migration load regarding this gene because $M C 1 R$ has no effect on survival and reproductive success in our local population.

The presence of $M C I R$ in the second-best survival model could suggest that selection is operating against the rufous coloration but the power to detect this effect is too low due to the fact that $M C 1 R$ only explains a third of the variation in color. Future studies combining survival and reproductive success of differentially colored individuals into a general framework, using for example demographic models and elasticity approach, are needed to validate this hypothesis.

\section{Data archiving}

Data (microsatellites and MC1R genotypes as well as the sex and year of capture of adult barn owls, the census data for the survival analysis, the fitness information) are available from the Dryad Digital Repository: https://doi.org/10. 5061/dryad.584g6qg.

Acknowledgements We thank the Swiss National Science Foundation for funding this study (31003A-120517 and 31003A_173178 to AR; 31003A_138180 to JG). The study was performed under legal authorization of the "Service vétérinaire du canton de Vaud." We also thank all former and current workers from the Roulin's group for the help in sampling and in DNA extraction.

Author contributions $\mathrm{AR}$ and JG obtained funding; VD, AR, and JG conceived and designed the study; VD collected the $M C 1 R$ and microsatellites data; AR conducted the field work; VD conducted the statistical and population genetic analyses; MS conducted the survival analysis; VD wrote the manuscript; and all the authors read and provided input on the manuscript. 


\section{Compliance with ethical standards}

Conflict of interest The authors declare that they have no conflict of interest.

\section{References}

Altwegg R, Jenkins A, Abadi F (2014) Nestboxes and immigration drive the growth of an urban Peregrine Falcon Falco peregrinus population. Ibis 156:107-115

Altwegg R, Roulin A, Kestenholz M, Jenni L (2003) Variation and covariation in survival, dispersal, and population size in barn owls Tyto alba. J Avian Ecol 72:391-399

Antoniazza S, Burri R, Fumagalli L, Goudet J, Roulin A (2010) Local adaptation maintains clinal variation in melanin-based coloration of European barn owls (Tyto alba). Evolution 64:1944-1954

Antoniazza S, Kanitz R, Neuenschwander S, Burri R, Gaigher A, Roulin A et al (2014) Natural selection in a postglacial range expansion: the case of the colour cline in the European barn owl. Mol Ecol 23:5508-5523

Baguette M (2003) Long distance dispersal and landscape occupancy in a metapopulation of the cranberry fritillary butterfly. Ecography 26:153-160

Balloux F (2001) EASYPOP (version 1.7): a computer program for the simulation of population genetics. Heredity 92:301-302

Barton K (2016) Multi-model inference. R package version 1.15.6. https://cran.r-project.org/web/packages/MuMIn/

Bennett DC, Lamoreux ML (2003) The color loci of mice - a genetic century. Pigment Cell Res 16:333-344

Berg EC, Eadie JM, Langen TA, Russell AF (2009) Reverse sexbiased philopatry in a cooperative bird: genetic consequences and a social cause. Mol Ecol 18:3486-3499

Biek R, Akamine N, Schwartz MK, Ruth TK, Murphy KM, Poss M (2006) Genetic consequences of sex-biased dispersal in a solitary carnivore: yellowstone cougars. Biol Lett 2:312-315

Boileau MG, Hebert PDN, Schwartz SS (1992) Non-equilibrium gene frequency divergence: persistent founder effects in natural populations. J Evol Biol 5:25-39

Bolnick DI, Nosil P (2007) Natural selection in populations subject to a migration load. Evolution 61:2229-2243

Bolnick DI, Otto SP (2013) The magnitude of local adaptation under genotype-dependent dispersal. Ecol Evol 3:4722-4735

Bourne EC, Bocedi G, Travis JM, Pakeman RJ, Brooker RW, Schiffers K (2014) Between migration load and evolutionary rescue: dispersal, adaptation and the response of spatially structured populations to environmental change. Proc Biol Sci 281:20132795

Burnham KP, Anderson DR, Huyvaert KP (2011) AIC model selection and multimodel inference in behavioral ecology: some background, observations, and comparisons. Behav Ecol Sociobiol 65:23-35

Burri R, Antoniazza S, Gaigher A, Ducrest AL, Simon C, European Barn Owl N et al (2016) The genetic basis of color-related local adaptation in a ring-like colonization around the Mediterranean. Evolution 70:140-153

Camacho C, Canal D, Potti J (2013) Nonrandom dispersal drives phenotypic divergence within a bird population. Ecol Evol 3:4841-4848

Chakarov N, Jonker RM, Boerner M, Hoffman JI, Kruger O (2013) Variation at phenological candidate genes correlates with timing of dispersal and plumage morph in a sedentary bird of prey. Mol Ecol 22:5430-5440

Chambers JL, Garant D (2010) Determinants of population genetic structure in eastern Chipmunks (Tamias striatus): the role of landscape barriers and sex-biased dispersal. J Hered 101:413-422
Charter M, Peleg O, Leshem Y, Roulin A (2012) Similar patterns of local barn owl adaptation in the Middle East and Europe with respect to melanic coloration. Biol J Linn Soc 106:447-454

Chen C, Burton M, Greenberg E, Dmitrieva J (1999) Population migration and the variation of dopamine D4 receptor (DRD4) allele frequencies around the globe. Evol Hum Behav 20:309-324

Choquet R, Lebreton J-D, Gimenez O, Reboulet A-M, Pradel R (2009) U-CARE: utilities for performing goodness of fit tests and manipulating CApture-REcapture data. Ecography 32:1071-1074

Ciani AC, Capiluppi C (2011) Gene flow by selective emigration as a possible cause for personality differences between small islands and mainland populations. Eur J Personal 25:53-64

Conrad KF, Willson KH, Harvey IF, Thomas CJ, Sherratt TN (1999) Dispersal characteristics of seven odonate species in an agricultural landscape. Ecography 22:524-531

Cooke SJ, Hinch SG, Wikelski M, Andrews RD, Kuchel LJ, Wolcott TG et al (2004) Biotelemetry: a mechanistic approach to ecology. Trends Ecol Evol 19:334-343

Cote J, Clobert J, Brodin T, Fogarty S, Sih A (2010) Personalitydependent dispersal: characterization, ontogeny and consequences for spatially structured populations. Philos Trans R Soc Lond B Biol Sci 365:4065-4076

Dreiss AN, Antoniazza S, Burri R, Fumagalli L, Sonnay C, Frey C et al (2012) Local adaptation and matching habitat choice in female barn owls with respect to melanic coloration. J Evol Biol 25:103-114

Dreiss AN, Roulin A (2010) Age related change in melanin based coloration of Barn owls (Tyto alba): females that become more female-like and males that become more male-like perform better. Biol J Linn Soc 101:689-704

Ducrest AL, Keller L, Roulin A (2008) Pleiotropy in the melanocortin system, coloration and behavioural syndromes. Trends Ecol Evol 23:502-510

Ducret V, Gaigher A, Simon C, Goudet J, Roulin A (2016) Sexspecific allelic transmission bias suggests sexual conflict at MC1R. Mol Ecol 25:4551-4563

Edelaar P, Bolnick DI (2012) Non-random gene flow: an underappreciated force in evolution and ecology. Trends Ecol Evol 27:659-665

Fraisse C, Roux C, Welch JJ, Bierne N (2014) Gene-flow in a mosaic hybrid zone: is local introgression adaptive? Genetics 197:939-951

Fulgione D, Rippa D, Bulgione M, Trapanese M, Petrelli S, Maselli V (2016) Unexpected but welcome. Artificially selected traits may increase fitness in wild boar. Evolutionary Applications 9:769-776

Garcia-Navas V, Ferrer ES, Sanz JJ, Ortego J (2014) The role of immigration and local adaptation on fine-scale genotypic and phenotypic population divergence in a less mobile passerine. $\mathrm{J}$ Evol Biol 27:1590-1603

Garcia-Ramos G, Kirkpatrick M (1997) Genetic models of adaptation and gene flow in peripheral populations. Evolution 51:21-28

Goudet J (1995) FSTAT (version1.2): a computer program to calculate $F$-statistics. J Hered 86:485-486

Goudet J (2005) HIERFSTAT, a package for R to compute and test hierarchical $F$-statistics. Mol Ecol Notes 5:184-186

Goudet J, Perrin N, Waser P (2002) Tests for sex-biased dispersal using bi-parentally inherited genetic markers. Mol Ecol 11:1103-1114

Greenwood PJ (1980) Mating systems, philopatry and dispersal in birds and mammals. Anim Behav 28:1140-1162

Hansson B, Bensch S, Hasselquist D (2003) A new approach to study dispersal: immigration of novel alleles reveals female-biased dispersal in great reed warblers. Mol Ecol 12:631-637 
Harrison XA, York JE, Young AJ (2014) Population genetic structure and direct observations reveal sex-reversed patterns of dispersal in a cooperative bird. Mol Ecol 23:5740-5755

Helfer V, Broquet T, Fumagalli L (2012) Sex-specific estimates of dispersal show female philopatry and male dispersal in a promiscuous amphibian, the alpine salamander (Salamandra atra). Mol Ecol 21:4706-4720

Hervé M (2016) RVAideMemoire: diverse basic statistical and graphical functions (R Package Version 0.9-62). https://cran.rproject.org/web/packages/RVAideMemoire/.

$\mathrm{Hu}$ XS, Li B (2003) On migration load of seeds and pollen grains in a local population. Heredity 90:162-168

Knutsen H, Olsen EM, Jorde PE, Espeland SH, Andre C, Stenseth NC (2011) Are low but statistically significant levels of genetic differentiation in marine fishes 'biologically meaningful'? A case study of coastal Atlantic cod. Mol Ecol 20:768-783

Lebreton J-D, Burnham KP, Clobert J, Anderson DR (1992) Modeling survival and testing biological hypotheses using marked animals: a unified approach with case studies. Ecol Monogr 62:67-118

Lenormand T (2002) Gene flow and the limits to natural selection. Trends Ecol Evol 17:183-189

Liebgold EB, Gerlach NM, Ketterson ED (2013) Similarity in temporal variation in sex-biased dispersal over short and long distances in the dark-eyed junco, Junco hyemalis. Mol Ecol 22:5548-5560

Mabry KE, Shelley EL, Davis KE, Blumstein DT, Van Vuren DH (2013) Social mating system and sex-biased dispersal in mammals and birds: a phylogenetic analysis. PLoS ONE 8:e57980

Mullen LM, Hoekstra HE (2008) Natural selection along an environmental gradient: a classic cline in mouse pigmentation. Evolution 62:1555-1570

Ortego J, Aparicio JM, Cordero PJ, Calabuig G (2008) Individual genetic diversity correlates with the size and spatial isolation of natal colonies in a bird metapopulation. Proc Biol Sci 275:2039-2047

Pakanen V-M, Koivula K, Orell M, Rytkönen S, Lahti K (2016) Sexspecific mortality costs of dispersal during the post-settlement stage promote male philopatry in a resident passerine. Behav Ecol Sociobiol 70:1727-1733

Palmer DH, Kronforst MR (2015) Divergence and gene flow among Darwin's finches: a genome-wide view of adaptive radiation driven by interspecies allele sharing. Bioessays 37:968-974

Palo JU, Lesbarreres D, Schmeller DS, Primmer CR, Merila J (2004) Microsatellite marker data suggest sex-biased dispersal in the common frog Rana temporaria. Mol Ecol 13:2865-2869

Paquette SR, Louis Jr. EE, Lapointe FJ (2010) Microsatellite analyses provide evidence of male-biased dispersal in the radiated tortoise Astrochelys radiata (Chelonia: Testudinidae). J Hered 101:403-412

Portnoy DS, Puritz JB, Hollenbeck CM, Gelsleichter J, Chapman D, Gold JR (2015) Selection and sex-biased dispersal in a coastal shark: the influence of philopatry on adaptive variation. Mol Ecol 24:5877-5885

Postma E, van Noordwijk AJ (2005) Gene flow maintains a large genetic difference in clutch size at a small spatial scale. Nature 433:65-68

R Core Team (2013) R: a language and environment for statistical computing. R Foundation for Statistical Computing, Vienna, Austria

Reissmann M, Ludwig A (2013) Pleiotropic effects of coat colourassociated mutations in humans, mice and other mammals. Semin Cell Dev Biol 24:576-586
Ronce O, Clobert J (2012) Dispersal syndromes. In: Clobert J, Baguette M, Benton TG, Bullock JM (eds) Dispersal ecology and evolution. Oxford University Press, Oxford

Ropert-Coudert Y, Wilson RP (2005) Trends and perspectives in animal-attached remote sensing. Front Ecol Environ 3:437-444

Roulin A (2004) Covariation between plumage colour polymorphism and diet in the Barn Owl Tyto alba. Ibis 146:509-517

Roulin A (2013) Ring recoveries of dead birds confirm that darker pheomelanic Barn Owls disperse longer distances. J Ornithol 154:871-874

Roulin A, Ducrest AL (2011) Association between melanism, physiology and behaviour: a role for the melanocortin system. Eur J Pharmacol 660:226-233

San-Jose LM, Ducrest AL, Ducret V, Beziers P, Simon C, Wakamatsu $\mathrm{K}$ et al (2015) Effect of the MC1R gene on sexual dimorphism in melanin-based colorations. Mol Ecol 24:2794-2808

Schaub M, Jakober H, Stauber W (2013) Strong contribution of immigration to local population regulation: evidence from a migratory passerine. Ecology 94:1828-1838

Schaub M, von Hirschheydt J, Gruebler MU (2015) Differential contribution of demographic rate synchrony to population synchrony in barn swallows. J Anim Ecol 84:1530-1541

Schtickzelle N, Mennechez G, Baguette M (2006) Dispersal depression with habitat fragmentation in the bog fritillary butterfly. Ecology 87:1057-1065

Simpson RK, Johnson MA, Murphy TG (2015) Migration and the evolution of sexual dichromatism: evolutionary loss of female coloration with migration among wood-warblers. Proc Biol Sci 282:20150375

Slatkin M (1985) Gene flow in natural populations. Ann Rev Ecol Syst 16:393-430

Slatkin M (1987) Gene flow and the geographic structure of natural populations. Science 236:787-792

Sonerud GA, Steen R, Selas V, Aanonsen OM, Aasen GH, Fagerland $\mathrm{KL}$, et al (2014) Evolution of parental roles in provisioning birds: diet determines role asymmetry in raptors. Behav Ecol 25:762-772

Tarka M, Akesson M, Hasselquist D, Hansson B (2014) Intralocus sexual conflict over wing length in a wild migratory bird. Am Nat 183:62-73

Trochet A, Courtois EA, Stevens VM, Baguette M, Chaine AS, Schmeller DS, et al (2016) Evolution of sex-biased dispersal Q Rev Biol 91:297-320

van den Brink V, Dreiss AN, Roulin A (2012) Melanin-based coloration predicts natal dispersal in the barn owl, Tyto alba. Anim Behav 84:805-812

van Dijk RE, Covas R, Doutrelant C, Spottiswoode CN, Hatchwell BJ (2015) Fine-scale genetic structure reflects sex-specific dispersal strategies in a population of sociable weavers (Philetairus socius). Mol Ecol 24:4296-4311

Wahlund S (1928) Zusammensetzung von populationen und korrelationserscheinungen vom standpunkt der vererbungslehre aus betrachtet. Hereditas 11:65-106

Watts PC, Rousset F, Saccheri IJ, Leblois R, Kemp SJ, Thompson DJ (2007) Compatible genetic and ecological estimates of dispersal rates in insect (Coenagrion mercuriale: Odonata: Zygoptera) populations: analysis of 'neighbourhood size' using a more precise estimator. Mol Ecol 16:737-751

White GC, Burnham KP (1999) Program MARK: survival estimation from populations of marked animals. Bird Study 46:120-139

Wright S (1943) Isolation by distance. Genetics 28:114-138

Wright S (1951) The genetical structure of populations. Ann Eugen $15: 323-354$ 